\title{
Two kinds of Online Retailers' Price Competition on B2C Market
}

\author{
Hao Fu' ${ }^{1}$, Jieyao Ding ${ }^{2}$, Leilei Liu ${ }^{2}$ \\ 1 Hao Fu, Herbert A.Simon \& Reinhard Selten Behavioral Decision \\ Research Lab, School of Economics and Management, \\ Southwest Jiaotong University, ChengDu 610031, China \\ 86-28-87600895; 13808177037; Haofu12@126.com \\ 2 Jieyao Ding, Leilei Liu, Herbert A.Simon \& Reinhard Selten \\ Behavioral Decision Research Lab, School of Economics and \\ Management, Southwest Jiaotong University, ChengDu 610031, \\ China
}

\begin{abstract}
Using game theory as research tool, this paper investigates deeply on price competition behavior between Multi-Channel Retailers (MCRs) and Pure Online Retailers (Dotcoms) on e-commerce market, elicits four kinds of market structures. Furthermore, it gives out perfect equilibrium prices as well as market scale under each condition of market structure. On this basis, two related propositions and two related conclusions are pointed out. First, it gets MCRs' and Dotcoms' critical prices. Secondly, as the penetrate rate of ebusiness increasing, two kind retailers' perfect prices will decrease, and there exists a stable relationship between the ratios of speed declining.
\end{abstract}

\section{Introduction}

At the beginning of Internet arisen, basing on the cognitive of Internet information technology's characteristic, people hold that on the e-business market, through investing even less than on traditional economic, consumers can search and face with more suppliers which may leads competition among suppliers. As a result, the consumers can get a lower price. In terms of economics, comparing with traditional off-line trade mode, e-business possesses higher market efficiency and lower market friction, reduces trade and search cost effectively, and consequently decreases suppliers' monopoly profit $[1,2]$. The so-called "free-friction trade hypothesis" which can be tested directly through comparing price level on e-business market attracts many researchers doing theoretical and empirical studies on comparing price competition between online retailers and off-line retailers [3]. It can be concluded that existent researches on modeling the price competition between traditional retailers and online retailers have been developed sufficiently [4]. 
However it is noticeable that, recent years, along with online market's expanding, more and more traditional retailers enter into $\mathrm{B} 2 \mathrm{C}$ market. As multi-channel retailers (MCRs), they compete directly with pure online retailers (Dotcoms). But there is little research on the price competition between these two kind of online retailers within online market's internal. In existing references, an important analytical model and empirical analysis paper investigate on price competition between MCRs and Dotcoms based on Hoterlling model [5]. As the author said, their "analytic model is based on Hotelling's linear city framework and is limited by its assumptions. Relaxing some of the assumption can make the model richer, albeit more complex". Moreover, Friberg [6] gave out a more general model about price competition between MCRs and Dotcoms, and did relevant empirical researches. But in his research work, the effect of e-business's penetrate rate (equal to number of Internet users/total population) on price competition is not taken into consider. Therefore, regarding two kind of retailers internal e-business market as research object, based on Friberg [6,7] and Cheng Yun's [8]modeling methodology about price competition between traditional off-line retailers and pure online retailers, this paper makes further development and generalization in order to get a more clear recognize on price competition between MCRs and Dotcoms.

According to O'keefe and McEachern's[9] consumer's decision making model, when consumers are conscious about the imbalance between ideal consuming and practical consuming, they face with channel choosing problem "where to buy" after decide what goods to buy for the purpose of offsetting this imbalance. Therefore, we suppose that: in the era of e-economic, when consumers who can purchase online choose their shopping mode (where to buy), there are two layers for them to make choice:1) purchase online or off-line; 2) if choose purchase online, then weigh the two online purchasing channels: MCR and Dotcoms. So researching on consumers' decision making between two online purchasing channels, this paper boosts existed results from working over price competition between traditional retailers and online retailers into two kind of retailers' competition in online market internal.

\section{Hypothesis}

Basing on previous statement, we first divide retail market into two parts: traditional off-line market and e-business online market. Then by setting up game model, compartmentalize market share among off-line channel and on-line channel respectively. Further, do more game analysis on price competition between MCRs and Dotcoms. In short, this paper divides the retail market into the following structures (figure 1): 


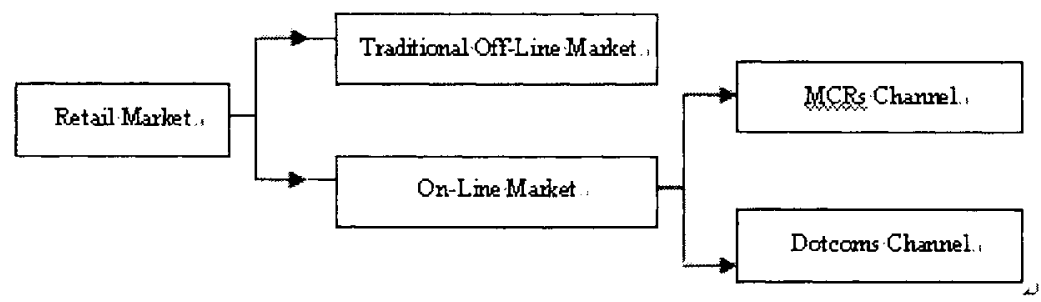

Figure. 1 Channel Division for Retail Market

According to consumers' choices-online/offline and different parameter relationships, various market structures are built. Consumers who choose purchasing online will make second layer choices-MCRs or Dotcoms. Concretely, when $\theta_{\mathrm{e}} \geqslant \theta_{\mathrm{t}}$ $\left\langle\theta_{e}\right.$, Utility consumers gain when they purchase online; $\theta_{\mathrm{t}}$, Utility consumers gain when they purchase off-line $)$, there $\operatorname{arev}(1-\hat{\theta})(v$ degree of e-business is actualized; $\theta$ critical evaluate value of consumers who choose e-business) consumers who choose purchase online; when $\theta_{\mathrm{e}}<\theta_{\mathrm{t}}$, there are $\vee\left(1-\theta_{\mathrm{e}}\right)$ consumers who choose purchase online. For simple, under these two conditions, this paper analysis further on price competition between MCRs and Dotcoms.

For the consumers who surely purchase online (online consumer), there are two kinds of online retailers -MCRs and Dotcoms on e-business market, therefore they have to choose purchasing channel from MCRs and Dotcoms.

Suppose utility function that online consumers choose MCRs or Dotcoms

$$
U(\theta)=\left\{\begin{array}{l}
\theta-p_{m}-t_{m} \theta \\
\theta-p_{d}-t_{d} \theta
\end{array}\right.
$$

1) $\theta$, consumer's evaluation on commodity $(U \leq \forall \leq 1)$, utility that consumer gains when purchase a commodity. Meanwhile hypotheses is $\theta$ uniformity distributed on $[0,1]$.

2) $P_{m}$, commodity's price when consumer purchases on MCRs,

$P_{d}$ commodity's price when consumer purchases on Dotcoms.

3) $t_{m}$, commodity's opportunity cost coefficient when consumer purchases on MCRs $\left(0<\mathrm{t}_{\mathrm{m}}<1\right)$

$t_{d}$, commodity's opportunity cost coefficient when consumer purchases on Dotcoms $\left(0<\mathrm{t}_{\mathrm{d}}<1\right)$;

Therefore, consumers' critical value evaluations on MCRs and Dotcoms are respectively

$$
\theta_{m}=\frac{p_{m}}{1-t_{m}} ; \quad \theta_{d}=\frac{p_{d}}{1-t_{d}}
$$

Next, we analysis different market structures formed by price competition between MCRs and Dotcoms based on the value of $\theta_{\mathrm{m}}$ and $\theta_{\mathrm{d}}$ 


\section{Division of market structure}

\subsection{When the number of online consumer is $v(1-\hat{\theta})$,}

\subsubsection{When $\theta_{\mathrm{m}} \geq \theta_{\mathrm{d}}\left(\theta_{\mathrm{e}}=\theta_{\mathrm{d}}\right)$}

Here, the consumer whose critical evaluation value is $\theta_{\mathrm{m}}$ or on the right of the axis can choose both MCRs and Dotcoms which means $v\left(1-\theta_{m}\right)$ consumers can choose either way. For these consumers, when they choose MCRs, it is necessary that

$$
\text { that's } \begin{aligned}
& \theta-t_{m} \theta-P_{m} \geq \theta-t_{d} \theta-P_{d}, \\
& \left(t_{d}-t_{m}\right) \theta \geq P_{m}-P_{d}
\end{aligned}
$$

Therefore, when $t_{d}-t_{m}>0$, the consumer whose value evaluation is between $\left(\left(\mathrm{P}_{\mathrm{m}}-\mathrm{P}_{\mathrm{d}}\right) /\left(\mathrm{t}_{\mathrm{d}}-\mathrm{t}_{\mathrm{m}}\right), 1\right)$ will choose MCRs, and the consumer whose value evaluation is between $\left(\hat{\theta},\left(\mathrm{P}_{\mathrm{m}}-\mathrm{P}_{\mathrm{d}}\right) /\left(\mathrm{t}_{\mathrm{d}}-\mathrm{t}_{\mathrm{m}}\right)\right)$ will choose Dotcoms.

When $t_{d}-t_{m}<0$, the consumer whose value evaluation is between $\left(\hat{\theta},\left(P_{m}-P_{d}\right) /\left(t_{d}-\right.\right.$ $\left.t_{m}\right)$ will choose MCRs, and the consumer whose value evaluation is between $\left(\left(P_{m}-\right.\right.$ $\left.\left.P_{d}\right) /\left(t_{d}-t_{m}\right), 1\right)$ will choose Dotcoms.

Concretely, because $\theta_{m} \geq \theta_{d}, P_{m} /\left(1-t_{m}\right) \geq P_{d} /\left(1-t_{d}\right)$, then $\left(P_{m}-P_{d}\right)\left(1-t_{m}\right) \geq\left(t_{d}-t_{m}\right) P_{m}$

When $t_{d}-t_{m}>0,\left(P_{m}-P_{d}\right) /\left(t_{d}-t_{m}\right) \geq \theta_{m}$, here critical evaluation of the consumers who choose MCRs finally is $\breve{\theta}=\left(\mathrm{P}_{\mathrm{m}}-\mathrm{P}_{\mathrm{d}}\right) /\left(\mathrm{t}_{\mathrm{d}}-\mathrm{t}_{\mathrm{m}}\right)$. Price competition in MCRs and Dotcoms form the market structure as follows,

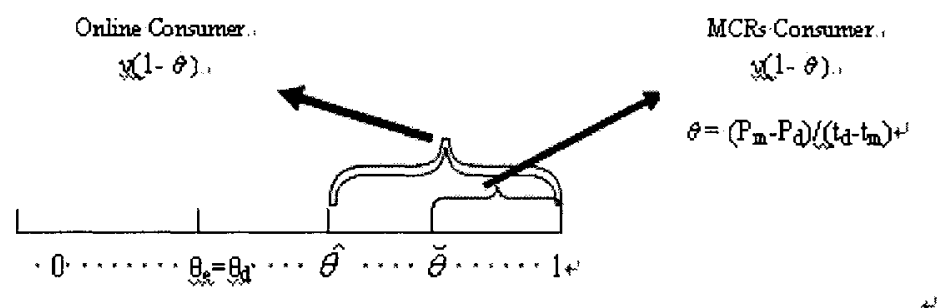

Figure. 2. Market Structure One Formed from Price Competition Between MCRs and Dotcoms

when $t_{d}-t_{m}<0,\left(P_{m}-P_{d}\right) /\left(t_{d}-t_{m}\right) \leqslant \theta_{m}$, here consumers who choose MCRs finally is empty which means MCRs's market share is zero. We focus on analysis of competition between MCRs and Dotcoms in online market and this condition is excluded from our research area, so we don't take it into consider.

Market Structure One:

Under the condition that the number of online consumer is $v(1-\hat{\theta}), \theta_{\mathrm{m}} \geq \theta_{\mathrm{d}}$, when and only when $t_{d}-t_{m}>0$, there exists a market structure that MCRs and Dotcoms coexist. Then, there are $v(1-\hat{\theta})$ consumers choose purchasing on MCRs, and there 
are $v(\breve{\theta}-\hat{\theta})$ consumers choose purchasing on Dotcoms.

3.1.2 When $\theta_{\mathrm{m}}<\theta_{\mathrm{d}}\left(\theta_{\mathrm{e}}=\theta_{\mathrm{m}}\right)$

Here, the consumer whose critical evaluation value is $\theta_{d}$ or on the right of the axis can choose both MCRs and Dotcoms which means $v\left(1-\theta_{d}\right)$ consumers can choose either way. For these consumers, when they choose MCRs, it is necessary that

$$
\theta-t_{m} \theta-P_{m} \geq \theta-t_{d} \theta-P_{d}
$$

So that $\quad\left(t_{d}-t_{m}\right) \theta \geq P_{m}-P_{d}$

Therefore, when $t_{d}-t_{m}>0$, the consumer whose value evaluation is between $\left(\left(P_{m}-P_{d}\right) /\left(t_{d}-t_{m}\right), 1\right)$ will choose MCRs, and the consumer whose value evaluation is between $\left(\hat{\theta},\left(\mathrm{P}_{\mathrm{m}}-\mathrm{P}_{\mathrm{d}}\right) /\left(\mathrm{t}_{\mathrm{d}}-\mathrm{t}_{\mathrm{m}}\right)\right)$ will choose Dotcoms.

When $t_{d}-t_{m}<0$, the consumer whose value evaluation is between $\left(\hat{\theta},\left(P_{m}-\right.\right.$ $\left.P_{d}\right) /\left(t_{d}-t_{m}\right)$ ) will choose MCRs, and the consumer whose value evaluation is between $\left(\left(P_{m}-P_{d}\right) /\left(t_{d}-t_{m}\right), 1\right)$ will choose Dotcoms.

$$
\begin{aligned}
& \because \theta_{m}<\theta_{d} \therefore P_{m} /\left(1-t_{m}\right)<P_{d} /\left(1-t_{d}\right) \quad \therefore\left(1-t_{d}\right) P_{m}<\left(1-t_{m}\right) P_{d} \\
& P_{m}-P_{d}<\left(t_{d} P_{m}-t_{m} P_{m}\right)+\left(t_{m} P_{m}-t_{m} P_{d}\right) \quad\left(1-t_{m}\right)\left(P_{m}-P_{d}\right)<\left(t_{d}-t_{m}\right) P_{m}
\end{aligned}
$$

So that: when $t_{d}-t_{m}>0$, that $\left(P_{m}-P_{d}\right) /\left(t_{d}-t_{m}\right)<\theta_{m}=\theta_{e}$

Because at this time, the number of consumer who choose Dotcoms is ( $\ddot{\theta},\left(\mathrm{P}_{\mathrm{m}^{-}}\right.$ $\left.\left.\mathrm{P}_{\mathrm{d}}\right) /\left(\mathrm{t}_{\mathrm{d}}-\mathrm{t}_{\mathrm{m}}\right)\right)$, it has been proved before that $\hat{\theta}>\theta_{\mathrm{e}}$ so it is not taken into consider.

Price competition in MCRs and Dotcoms form the market structure as follows

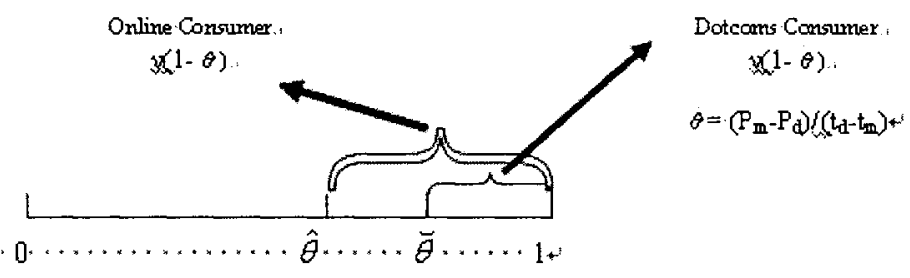

Figure. 3. Market Structure Two Formed from Price Competition Between MCRs and Dotcoms

Market Structure Two:

Under the condition that the number of online consumer is $v(1-\hat{\theta}), \theta_{\mathfrak{m}}<\theta_{\mathrm{d}}$, when and only when $t_{d}-t_{m}<0$, there exists a market structure that MCRs and Dotcoms coexist. Then, there $\operatorname{arev}(\ddot{\theta}-\hat{\theta})$ consumers choose who purchasing on MCRs, and there are $v(1-\bar{\theta})$ consumers who choosing purchase on Dotcoms. 


\subsection{When the number of online consumer is $v(1-\theta e)$,}

3.2.1 When $\theta_{\mathrm{m}} \geq \theta_{\mathrm{d}}: \quad\left(\theta_{\mathrm{e}}=\theta_{\mathrm{d}}\right)$

Here, theconsumer whose critical evaluation value is $\theta_{\mathrm{m}}$ or on the right of the axis can choose both MCRs and Dotcoms which means $v\left(1-\theta_{m}\right)$ consumers can choose both purchasing way. For these consumers, when they choose MCRs, it is necessary that

$$
\text { that's } \quad \begin{aligned}
& \theta-t_{m} \theta-P_{m} \geq \theta-t_{d} \theta-P_{d}, \\
& \left(t_{d}-t_{m}\right) \theta \geq P_{m}-P_{d} .
\end{aligned}
$$

Therefore, when $t_{d}-t_{m}>0$, the consumer whose value evaluation is between $\left(\left(P_{m}-\right.\right.$ $\left.\left.P_{d}\right) /\left(t_{d}-t_{m}\right), 1\right)$ will choose MCRs, and the consumer whose value evaluation is between $\left(\theta_{e},\left(P_{m}-P_{d}\right) /\left(t_{d}-t_{m}\right)\right)$ will choose Dotcoms.

When $t_{d}-t_{m}<0$, the consumer whose value evaluation is between $\left(\theta_{e},\left(P_{m}-P_{d}\right) /\left(t_{d}-\right.\right.$ $\left.t_{m}\right)$ ) will choose MCRs, and the consumer whose value evaluation is between $\left(\left(P_{m}-\right.\right.$ $\left.\left.P_{d}\right) /\left(t_{d}-t_{m}\right), 1\right)$ will choose Dotcoms.

Concretely, because $\theta_{m} \geq \theta_{d}, P_{m} /\left(1-t_{m}\right) \geq P_{d} /\left(1-t_{d}\right)$, then $\left(P_{m}-P_{d}\right)\left(1-t_{m}\right) \geq\left(t_{d}-t_{m}\right) P_{m}$

When $t_{d}-t_{m}>0,\left(P_{m}-P_{d}\right) /\left(t_{d}-t_{m}\right) \geq \theta_{m}$, here critical evaluation of the consumers who choose MCRs finally is $\breve{\theta}=\left(\mathrm{P}_{\mathrm{m}}-\mathrm{P}_{\mathrm{d}}\right) /\left(\mathrm{t}_{\mathrm{d}}-\mathrm{t}_{\mathrm{m}}\right)$. Price competition in MCRs and Dotcoms form the market structure as follows

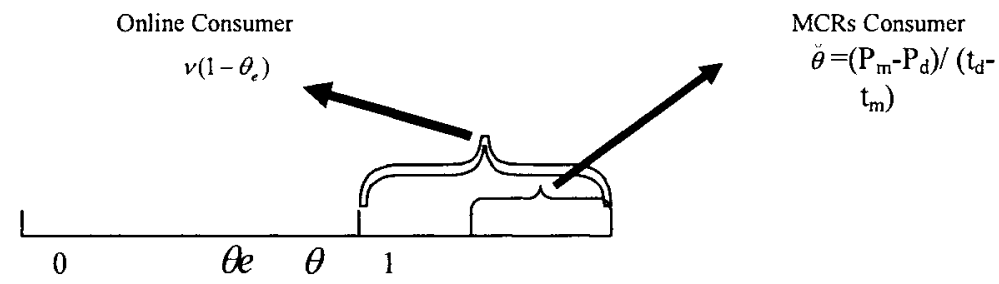

Figure. 4. Market Structure Three Formed from Price Competition Between MCRs and Dotcoms

When $t_{d}-t_{m}<0$, for $\theta_{m} \geq \theta_{d}$, then $P_{m} /\left(1-t_{m}\right) \geq P_{d} /\left(1-t_{d}\right)$.

So $P_{m}-P_{d} \geq t_{d} P_{m}-t_{m} P_{d}=\left(t_{d} P_{m}-t_{d} P_{d}\right)+\left(t_{d} P_{d}-t_{m} P_{d}\right)=t_{d}\left(P_{m}-P_{d}\right)+\left(t_{d}-t_{m}\right) P_{d}$

Because $t_{d}-t_{m}<0,\left(P_{m}-P_{d}\right) /\left(t_{d}-t_{m}\right) \leqslant P_{d} /\left(1-t_{d}\right)$, that's $\ddot{\theta} \leqslant \theta_{d}=\theta_{e}$, therefore value evaluation $\left(\theta_{e},\left(\mathrm{P}_{m}-\mathrm{P}_{d}\right) /\left(t_{d}-t_{m}\right)\right)$ of consumers who choose MCRs is empty one and it will be not taken into consider.

Market Structure Three:

Under the condition that the number of online consumer is $v\left(1-\theta_{\mathrm{e}}\right), \theta_{\mathrm{m}} \geq \theta_{\mathrm{d}}$, when and only when $t_{d}-t_{m}>0$, there exists a market structure that MCRs and Dotcoms coexist. Then, there are $v(1-\theta)$ consumers who choose purchasing on MCRs, and there are $v\left(\dot{\theta}-\theta_{\mathrm{e}}\right)$ consumers who choose purchasing on Dotcoms.

3.2.2 When $\theta_{\mathrm{m}}<\theta_{\mathrm{d}}\left(\theta_{\mathrm{e}}=\theta_{\mathrm{m}}\right)$ : 
Here, the consumer whose critical evaluation value is $\theta_{d}$ or on the right can choose both MCRs and Dotcoms which means v $\left(1-\theta_{d}\right)$ consumers can choose both purchasing way. For these consumers, when they choose MCRs, it is necessary that

$$
\theta-t_{m} \theta-P_{m} \geq \theta-t_{d} \theta-P_{d}
$$

Still that $\left(t_{d}-t_{m}\right) \theta \geq P_{m}-P_{d}$ 。

When $t_{d}-t_{m}>0$, the consumer whose value evaluation is between $\left(\left(P_{m}-P_{d}\right) /\left(t_{d}-t_{m}\right), 1\right)$ will choose MCRs, and the consumer whose value evaluation is between $\left(\theta_{e},\left(P_{m}{ }^{-}\right.\right.$ $\left.\left.P_{d}\right) /\left(t_{d}-t_{m}\right)\right)$ will choose Dotcoms.

When $t_{d}-t_{m}<0$, the consumer whose value evaluation is between $\left(\theta_{e},\left(P_{m}-P_{d}\right) /\left(t_{d}-\right.\right.$ $\left.t_{m}\right)$ ) will choose MCRs, and the consumer whose value evaluation is between $\left(\left(P_{m}-\right.\right.$ $\left.\left.P_{d}\right) /\left(t_{d}-t_{m}\right), 1\right)$ will choose Dotcoms.

$$
\begin{aligned}
& \because \theta_{m}<\theta_{d} \therefore P_{m} /\left(1-t_{m}\right)<P_{d} /\left(1-t_{d}\right) \therefore\left(1-t_{d}\right) P_{m}<\left(1-t_{m}\right) P_{d} \\
& P_{m}-P_{d}<\left(t_{d} P_{m}-t_{m} P_{m}\right)+\left(t_{m} P_{m}-t_{m} P_{d}\right) \quad\left(1-t_{m}\right)\left(P_{m}-P_{d}\right)<\left(t_{d}-t_{m}\right) P_{m}
\end{aligned}
$$

(a) when $t_{d}-t_{m}>0$, that $\left(P_{m}-P_{d}\right) /\left(t_{d}-t_{m}\right)<\theta_{m}$;

(b) when $t_{d}-t_{m}<0$, that $\left(P_{m}-P_{d}\right) /\left(t_{d}-t_{m}\right)>\theta_{m}$.

When $t_{d}-t_{m}>0$, evaluation cluster $\left(\theta_{e},\left(P_{m}-P_{d}\right) /\left(t_{d}-t_{m}\right)\right)$ of consumers who choose Dotcoms is empty.

Price competition in MCRs and Dotcoms form the market structures as follows

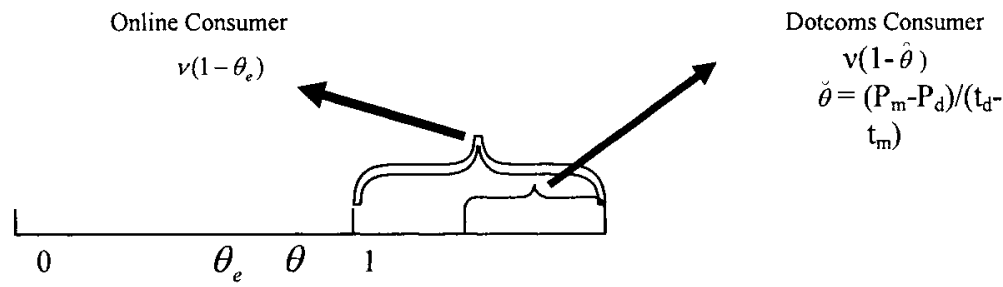

Figure. 5. Market Structure Four Formed from Price Competition Between MCRs and Dotcoms

\section{Market Structure Four:}

Under the condition that the number of online consumer is $v\left(1-\theta_{\mathrm{e}}\right), \theta_{\mathrm{m}}<\theta_{\mathrm{d}}$, when and only when $t_{d}-t_{m}<0$, there exists a market structure that MCRs and Dotcoms coexist. Then, there are $v(1-\check{\theta})$ consumers who choose purchase on Dotcoms, and there are $v\left(\breve{\theta}-\theta_{\mathrm{e}}\right)$ consumers who choose purchase on MCRs. 


\section{Game analysis under four market structure}

Using backward induction, we deduce two kinds of retailers' optimum prices and equilibrium solutions as follow:

The demands of consumers who choose purchasing channels of MCRs and Dotcoms are respectively:

$$
D_{m}=v\left(1-\frac{p_{m}-p_{d}}{t_{d}-t_{m}}\right) ; \quad D_{d}=v\left(\frac{p_{m}-p_{d}}{t_{d}-t_{m}}-\hat{\theta}\right)
$$

Profit functions are:

$$
\pi_{\mathrm{m}}=\left(\mathrm{P}_{\mathrm{m}}-\mathrm{C}_{\mathrm{m}}\right) \mathrm{D}_{\mathrm{m}} ; \pi_{\mathrm{d}}=\left(\mathrm{P}_{\mathrm{d}}-\mathrm{C}_{\mathrm{d}}\right) \mathrm{D}_{\mathrm{d}}
$$

Perfect price are respectively:

$$
\begin{aligned}
& p_{m}^{*}=-\frac{1}{3}\left(-c_{d}-2 c_{m}-2 t_{d}+\hat{\theta}_{d}+2 t_{m}-\hat{\theta}_{m}\right) \\
& p_{d}^{*}=-\frac{1}{3}\left(-2 c_{d}-c_{m}-t_{d}+2 \hat{\theta} t_{d}+t_{m}-2 \hat{\theta}_{m}\right)
\end{aligned}
$$

Therefore, equilibrium solutions are as follows:

$$
\begin{gathered}
\theta_{m}^{*}=-\frac{1}{3}\left(-c_{d}-2 c_{m}-2 t_{d}+\hat{\theta}_{d}+2 t_{m}-\hat{\theta}_{m}\right) /\left(1-t_{m}\right) \\
\theta_{d}^{*}=-\frac{1}{3}\left(-2 c_{d}-c_{m}-t_{d}+2 \hat{\theta}_{d}+t_{m}-2 \hat{\theta}_{m}\right) /\left(1-t_{d}\right) \\
\vec{\theta}^{*}=\frac{-c_{d}+c_{m}+(1+\hat{\theta})\left(t_{d}-t_{m}\right)}{3\left(t_{d}-t_{m}\right)} \quad D_{m}^{*}=\frac{v\left[c_{d}-c_{m}-(\hat{\theta}-2)\left(t_{d}-t_{m}\right)\right]}{3\left(t_{d}-t_{m}\right)} \\
\pi_{m}^{*}=\frac{v\left[-c_{d}+c_{m}+(\hat{\theta}-2)\left(t_{d}-t_{m}\right)\right]^{2}}{9\left(t_{d}-t_{m}\right)} \quad D_{d}^{*}=-\frac{v\left[c_{d}-c_{m}+(2 \hat{\theta}-1)\left(t_{d}-t_{m}\right)\right]}{3\left(t_{d}-t_{m}\right)} \\
\pi_{d}^{*}=\frac{v\left[c_{d}-c_{m}+(2 \hat{\theta}-1)\left(t_{d}-t_{m}\right)\right]^{2}}{9\left(t_{d}-t_{m}\right)}
\end{gathered}
$$

Similarly, perfect price and equilibrium solution of structure two are:

$$
\begin{aligned}
& p_{m}^{*}=-\frac{1}{3}\left(-c_{d}-2 c_{m}+t_{d}-2 \hat{\theta}_{d}-t_{m}+2 \hat{\theta}_{m}\right) \\
& p_{d}^{*}=-\frac{1}{3}\left(-2 c_{d}-c_{m}+2 t_{d}-\hat{\theta} t_{d}-2 t_{m}+\hat{\theta}_{m}\right)
\end{aligned}
$$




$$
\begin{aligned}
& \theta_{m}^{*}=-\frac{1}{3}\left(-c_{d}-2 c_{m}+t_{d}-2 \hat{\theta}_{d}-t_{m}+2 \hat{\theta}_{m}\right) /\left(1-t_{m}\right) \\
& \theta_{d}^{*}=-\frac{1}{3}\left(-2 c_{d}-c_{m}+2 t_{d}-\hat{\theta}_{d}-2 t_{m}+\hat{\theta}_{m}\right) /\left(1-t_{d}\right) \\
& \check{\theta}^{*}=\frac{-c_{d}+c_{m}+(1+\hat{\theta})\left(t_{d}-t_{m}\right)}{3\left(t_{d}-t_{m}\right)}
\end{aligned}
$$

And, perfect price and equilibrium solution of structure three are:

$$
\begin{aligned}
& p_{m}^{*}=-\frac{1}{3}\left(-c_{d}-2 c_{m}-2 t_{d}+\theta_{e} t_{d}+2 t_{m}-\theta_{e} t_{m}\right) \\
& p_{d}^{*}=-\frac{1}{3}\left(-2 c_{d}-c_{m}-t_{d}+2 \theta_{e} t_{d}+t_{m}-2 \theta_{e} t_{m}\right) \\
& \theta_{m}^{*}=-\frac{1}{3}\left(-c_{d}-2 c_{m}-2 t_{d}+\theta_{e} t_{d}+2 t_{m}-\theta_{e} t_{m}\right) /\left(1-t_{m}\right) \\
& \theta_{d}^{*}=-\frac{1}{3}\left(-2 c_{d}-c_{m}-t_{d}+2 \theta_{e} t_{d}+t_{m}-2 \theta_{e} t_{m}\right) /\left(1-t_{d}\right) \\
& \bar{\theta}^{*}=\frac{-c_{d}+c_{m}+\left(1+\theta_{e}\right)\left(t_{d}-t_{m}\right)}{3\left(t_{d}-t_{m}\right)}
\end{aligned}
$$

Last, perfect price and equilibrium solution of structure four are:

$$
\begin{gathered}
p_{m}^{*}=-\frac{1}{3}\left(-c_{d}-2 c_{m}+t_{d}-2 \theta_{e} t_{d}-t_{m}+2 \theta_{e} t_{m}\right) \\
p_{d}^{*}=-\frac{1}{3}\left(-2 c_{d}-c_{m}+2 t_{d}-\theta_{e} t_{d}-2 t_{m}+\theta_{e} t_{m}\right) \\
\theta_{m}^{*}=-\frac{1}{3}\left(-c_{d}-2 c_{m}+t_{d}-2 \theta_{e} t_{d}-t_{m}+2 \theta_{e} t_{m}\right) /\left(1-t_{m}\right) \\
\theta_{d}^{*}=-\frac{1}{3}\left(-2 c_{d}-c_{m}+2 t_{d}-\theta_{e} t_{d}-2 t_{m}+\theta_{e} t_{m}\right) /\left(1-t_{d}\right) \\
\bar{\theta}^{*}=\frac{-c_{d}+c_{m}+\left(1+\theta_{e}\right)\left(t_{d}-t_{m}\right)}{3\left(t_{d}-t_{m}\right)}
\end{gathered}
$$

\section{Discussion}

Basing on four kinds of MCRs and Dotcoms coexist market structures and each equilibrium solution confirmed by two-step game analysis, we can deduce other useful results including necessary condition of Nash equilibrium. As for the core of this paper-price competition between online sales channels MCRs and Dotcoms on e-business market internal, we can make conclusions through comparing two kinds of retailers' perfect prices in each market structure. Results are showed in Table1.

In order to simplify the condition $\mathrm{P}_{\mathrm{d}}{ }^{*}<\mathrm{P}_{\mathrm{m}}{ }^{*}$ showed above, we introduce parameter $s$ which stands for e-business market's scale. Obviously, $s$ is between $[0,1]$, and there exists relationships among four kinds of market structures: 


$$
s= \begin{cases}v(1-\hat{\theta}) & \text { market structure } 1 \text { and } 2 \Leftrightarrow \hat{\theta}=1-\frac{s}{v} \\ v\left(1-\theta_{e}\right) & \text { market structure } 3 \text { and } 4 \Leftrightarrow \theta_{c}=1-\frac{s}{v}\end{cases}
$$

Then we can unify the condition $\mathrm{P}_{\mathrm{d}}{ }^{*}<\mathrm{P}_{\mathrm{m}}{ }^{*}$ of four kinds of market structures

$$
\mathrm{C}_{\mathrm{d}}-\mathrm{C}_{\mathrm{m}}<(2-\mathrm{s} / \mathrm{v})\left(\mathrm{t}_{\mathrm{d}}-\mathrm{t}_{\mathrm{m}}\right)
$$

Come to following propositions:

Proposition 1: In the competition of e-business market that two kinds of online retailers coexist, four factors together decide the price of two kind online retailers:

retailers' cost $C_{m}$ and $C_{d}$, other cost parameters $t_{m}$ and $t_{d}$ that consumers perceive when they purchase from two kind of retailers, e-business market's scales and ebusiness penetrate rate $v$. When two kinds of retailers' cost difference is lower than a critical value $(2-s / v)\left(t_{d}-t_{m}\right)$, prior retailers' price is lower than the latter's. When the difference between costs that coefficient consumers perceive when they purchase from two kind of retailers is higher than a critical value $\left(C_{d}-C_{m}\right) v /(2 v-s)$, prior retailers' price is lower that the latter's.

Prove:

From $C_{d}-C_{m}<(2-s / v)\left(t_{d}-t_{m}\right)$ and relationship between $t_{d}$ and $t_{m}$ of four market 
Table 1 Competition Relationship Between MCRs and Dotcoms on E-Business Market

\begin{tabular}{|c|c|c|c|}
\hline $\begin{array}{l}\text { Market } \\
\text { Structure }\end{array}$ & $\begin{array}{r}\text { Relationship of } \\
\text { Parameter }\end{array}$ & $p_{m}^{*}-p_{d}^{*}$ & $\begin{array}{l}\text { Condition that Dotcoms's } \\
\text { price } \\
\text { is lower that MCRs's price }\end{array}$ \\
\hline 1 & $\begin{array}{l}\text { Online Market } \\
\quad \text { Scale } \\
v(1-\hat{\theta}), \\
\theta_{\mathrm{m}} \geq \theta_{\mathrm{d}}, \quad \mathrm{t}_{\mathrm{d}}>\mathrm{t}_{\mathrm{m}}\end{array}$ & $-\frac{c_{d}-c_{m}+(1+\hat{\theta})\left(t_{m}-t\right.}{3}$ & $\begin{array}{c}\mathrm{C}_{\mathrm{d}^{-}} \\
\mathrm{C}_{\mathrm{m}}<(1+\hat{\theta})\left(t_{d}-t_{m}\right)\end{array}$ \\
\hline 2 & $\begin{array}{l}\text { Online Market } \\
\quad \text { Scale } \\
v(1-\hat{\theta}) \\
\theta_{\mathrm{m}}<\theta_{\mathrm{d}}, \quad \mathrm{t}_{\mathrm{d}}<\mathrm{t}_{\mathrm{m}}\end{array}$ & & $\begin{array}{c}\mathrm{C}_{\mathrm{d}^{-}} \\
\mathrm{C}_{\mathrm{m}}<(1+\hat{\theta})\left(t_{d}-t_{m}\right)\end{array}$ \\
\hline 3 & $\begin{array}{l}\text { Online Market Scale } \\
\qquad v\left(1-\theta_{e}\right), \\
\theta_{m} \geq \theta_{d}, \quad t_{d}>t_{m}\end{array}$ & $-\frac{c_{d}-c_{m}+\left(1+\theta_{c}\right)\left(t_{m}\right.}{3}$ & $C_{d}-C_{m}<\left(1+\theta_{e}\right)\left(t_{d}-t_{m}\right)$ \\
\hline 4 & $\begin{array}{l}\text { Online Market Scale } \\
\qquad \begin{array}{r}v\left(1-\theta_{\mathrm{e}}\right), \\
\theta_{\mathrm{m}}<\theta_{\mathrm{d}}, \quad \mathrm{t}_{\mathrm{d}}<\mathrm{t}_{\mathrm{m}}\end{array}\end{array}$ & & $C_{d}-C_{m}<\left(1+\theta_{e}\right)\left(t_{d}-t_{m}\right)$ \\
\hline
\end{tabular}

structures, we can find that:

1) Under all four market structures, there is: when Dotcoms's cost $C_{d}<C_{m}+(2-s / v)$ $\left(t_{d}-t_{m}\right)$, Dotcoms's price is lower than MCRs's.

2) Under all four market structures, there is: when other parameters except price that consumer' perceive when they purchase on Dotcoms $t_{d}>t_{m}+\left(C_{d}-C_{m}\right) v /(2 v-s)$, Dotcoms's price is lower than MCRs's.

3) Under market structure 1 and 3, when e-business market scale $s<v\left(2-\left(\mathrm{C}_{d^{-}}\right.\right.$ $\left.\left.C_{m}\right) /\left(t_{d}-t_{m}\right)\right)$, Dotcoms's price is lower than MCRs's. Under market structure 2 and 4 , when e-business market scale $s>v\left(2-\left(C d-C_{m}\right) /\left(t_{d}-t_{m}\right)\right)$, Dotcoms's price is lower than MCRs's.

4) Under market structure 1 and 3, when e-business penetrate rate $v>s /\left(2-\left(C_{d^{-}}\right.\right.$ $\left.\left.C_{m}\right) /\left(t_{d}-t_{m}\right)\right)$, Dotcoms's price is lower than MCRs's; Under market structure 2 and 4 , when e-business penetrate rate $v<s /\left(2-\left(C_{d}-C_{m}\right) /\left(t_{d}-t_{m}\right)\right)$, Dotcoms's price is lower than MCRs's;

Finish.

Proposition 2: As e-business penetrate rate increasing, two kind retailers' perfect prices decrease and there is a stable relationship of ratio of decline speed; in market structure 1 and 3, the difference increase; and in market structure 2 and 4, the difference decrease.

Prove: 
Market Structure 1:

$$
\begin{aligned}
& \dot{p}_{m}^{*}=-\frac{1}{3}\left(-c_{d}-2 c_{m}-2 t_{d}+\left(1-\frac{s}{v}\right) t_{d}+2 t_{m}-\left(1-\frac{s}{v}\right) t_{m}\right)=\frac{1}{3}\left(-c_{d}-2 c_{m}+\left(1+\frac{s}{v}\right)\left(t_{m}-t_{d}\right)\right) \\
& \dot{p}_{d}^{*}=-\frac{1}{3}\left(-2 c_{d}-c_{m}-t_{d}+2\left(1-\frac{s}{v}\right) t_{d}+t_{m}-2\left(1-\frac{s}{v}\right) t_{m}\right)=\frac{1}{3}\left(-2 c_{d}-c_{m}+\left(1-\frac{2 s}{v}\right)\left(t_{d}-t_{m}\right)\right) \\
& p_{m}^{*}-p_{d}^{*}=-\frac{1}{3}\left(c_{d}-c_{m}+\left(2-\frac{s}{v}\right)\left(t_{m}-t_{d}\right)\right)
\end{aligned}
$$

Then

$$
\frac{\partial p_{m}^{*}}{\partial v}=\frac{\left(t_{m}-t_{d}\right) s}{3} * \frac{1}{v^{2}} \leq 0 ; \quad \frac{\partial p_{d}^{*}}{\partial v}=\frac{2\left(t_{m}-t_{d}\right) s}{3} * \frac{1}{v^{2}} \leq 0 ; \quad \frac{\partial\left(p_{m}^{*}-p_{d}^{*}\right)}{\partial v}=\frac{\left(t_{d}-t_{m}\right) s}{3} * \frac{1}{v^{2}} \geq 0
$$

Market Structure 2:

$$
\begin{aligned}
& p_{m}^{*}=-\frac{1}{3}\left(-c_{d}-2 c_{m}+t_{d}-2\left(1-\frac{s}{v}\right) t_{d}-t_{m}+2\left(1-\frac{s}{v}\right) t_{m}\right)=-\frac{1}{3}\left(-c_{d}-2 c_{m}+\left(1-\frac{2 s}{v}\right)\left(t_{m}-t_{d}\right)\right) \\
& p_{d}^{*}=-\frac{1}{3}\left(-2 c_{d}-c_{m}+2 t_{d}-\left(1-\frac{s}{v}\right) t_{d}-2 t_{m}+\left(1-\frac{s}{v}\right) t_{m}=-\frac{1}{3}\left(-2 c_{d}-c_{m}+\left(1+\frac{s}{v}\right)\left(t_{d}-t_{m}\right)\right)\right. \\
& p_{m}^{*}-p_{d}^{*}=-\frac{1}{3}\left(c_{d}-c_{m}+\left(2-\frac{s}{v}\right)\left(t_{m}-t_{d}\right)\right)
\end{aligned}
$$

Then

$$
\frac{\partial p_{m}^{*}}{\partial v}=\frac{2\left(t_{d}-t_{m}\right) s}{3} * \frac{1}{v^{2}} \leq 0 ; \quad \frac{\partial p_{d}^{*}}{\partial v}=\frac{\left(t_{d}-t_{m}\right) s}{3} * \frac{1}{v^{2}} \leq 0 ; \quad \frac{\partial\left(p_{m}^{*}-p_{d}^{*}\right)}{\partial v}=\frac{\left(t_{d}-t_{m}\right) s}{3} * \frac{1}{v^{2}} \leq 0
$$

Market Structure 3: similar with market structure 1.

Market Structure 4: similar with market structure 4.

Finish.

\section{Conclusion}

This paper is based on model (Friber [6,7]; ChengYun et al.[8]) that focuses on price competition problem between traditional off-line market retailers and pure online retailers, and develop it further into considering the price competition behavior of both Multi-Channel Retailers (MCRs) and Pure Online Retailers (Dotcoms) on ebusiness market. Furthermore, we calculate perfect equilibrium price of two kinds of e-business retailer under four types of market structure, introduce parameters that indicate the scale of e-business market, and discuss characteristic of the changes about pricing strategy and perfect price that belong to these two kinds of retailer.

This research not only consummates price competition behavior of doublechannel retailers on e-business market academically, but also provides theoretical foundation for further empirical research on e-business market pricing. Admittedly, 
we do not include other factors such as price competition behavior of MCRs's offline part and traditional offline retailers. It is worthy studying further on this part.

\section{References}

1. J.Y. Bakos, "Reducing Buyer Search Costs: Implications for Electronic Marketplaces", Management Science, 1997,43(12):1613-1630

2. J.Y. Bakos, "The Emerging Role of Electronic Marketplaces on the Internet", Communications of the $A C M, 1998,41(8): 35-42$

3. S. Balasubramanian, "Mail versus Mall: A Strategic Analysis of Competition between Direct Marketers and Conventional Retailers", Marketing Science, 1998,17(3):181-195

4. M.D. Smith, J. Baily, \& E. Brynjolfsson, "Understanding Digital Markets: Review and Assessment", In: E. Brynjolfssom \& B. Kahin(Eds). Understanding the Digital Economy. MIT press. 2000

5. X. Pan, V. Shankar, \& B. Ratchford, "Price Competition Between Pure Play vs. Bricks-andClicks e-Tailers: Analytical Model and Empirical Analysis". Advances in Applied Microeconomics, 2002,11:29-61

6. R. Friberg, M. Ganslandt, \& M. Sandström, "E-commerce and Price-theory and evidence", Working Paper, Stockholm School of Economics, 2000

7. R. Friberg, M. Ganslandt, \& M. Sandström, "Pricing Strategies in E-commerce: Bricks vs. Clicks", Working Paper, Stockholm School of Economics, 2001

8. Y. Chen, H,C, Wang, H.Z. Shen, "Study on the Price Competition between E-commerce Retailer and Conventional Retailer", Theory and Practice of Systematical Engineering (in Chinese), 2006 ( 1 ) : P35-41

9. R.M. O'keefe, \& T. McEachern, "Web-based Customer Decision Support System", Communications of the ACM, 1998,41(3):71-78 